\title{
Effect of dexmedetomidine on endotracheal intubating conditions during endotracheal intubation without neuromuscular blocker following propofol/remifentanil
}

\author{
YH Kim, JH Park, YJ Kim, YK Ko. \\ Department of Anesthesiology and Pain Medicine, Chungnam National University Hospital, Daejeon, Korea
}

\section{INTRODUCTION}

Propofol and remifentanil (2-4 $\mu \mathrm{g} / \mathrm{kg})$ are known to be able to induce a condition appropriate for endotracheal intubation without a neuromuscular blocking agent.

Dexmedetomidine as an adjuvant for induction of anesthesia is known to have sedative and airway reflex blunting effects, providing better conditions for awake fiberoptic intubation, awake blind nasotracheal intubation, and laryngeal mask airway placement when used with propofol. Thus, when performing endotracheal intubation without a neuromuscular blocker, dexmedetomidine may provide good intubating conditions without the use of a relatively high dose of remifentanil. In the present study, we investigated the effect of $1 \mu \mathrm{g} / \mathrm{kg}$ dexmedetomidine on the intubating conditions and hemodynamic changes during endotracheal intubation following anesthetic induction performed using propofol $2 \mathrm{mg} / \mathrm{kg}$ and remifentanil $1.5 \mu \mathrm{g} / \mathrm{kg}$ without a neuromuscular blocking agent

\section{PATIENTS AND METHODS}

We selected 70 adult patients aged 20 to 65 years scheduled to undergo general anesthesia. Induction was performed using $2 \mathrm{mg} / \mathrm{kg}$ of propofol and $1.5 \mu \mathrm{g} / \mathrm{kgg}$ of remifentanil. The patients were divided into two groups, a dexmedetomidine group (Group D) and a control group (Group C). Group D received an infusion of dexmedetomidine $1 \mu \mathrm{g} / \mathrm{kg}$ for 10 minutes before induction, and Group $\mathrm{C}$ received the same volume of normal saline infused in the same manner. Intubating conditions were evaluated and blood pressure and heart rate were recorded at various time points to assess hemodynamic stability.

Table 1. Assessment of Intubating Conditions (According to Cooper intubating conditions scale )

\begin{tabular}{cccc}
\hline Score & Laryngoscopy & Condition of & Response to \\
& vocal cords & intubation \\
\hline 0 & Poor (impossible) & Closed & Severe coughing or \\
& Minimal (difficult) & Closing & Mild coughing \\
1 & Moderate (fair) & Moving & Slight diaphragmatic \\
2 & & & movement \\
& Good (easy) & Open & None \\
\hline
\end{tabular}

Table 2. Intubating Conditions Classification (According to Cooper intubating conditions scale)

\begin{tabular}{ccccc}
\hline Points & $8-9$ & $6-7$ & $3-5$ & $0-2$ \\
\hline $\begin{array}{l}\text { Intubating } \\
\text { conditions }\end{array}$ & Excellent & Good & Poor & bad \\
\hline
\end{tabular}

Table 3. Patients Characteristics

\begin{tabular}{lcc}
\hline & Group C $(\mathrm{n}=35)$ & Group D $(\mathrm{n}=35)$ \\
\hline Female/Male & $24 / 11$ & $27 / 8$ \\
Age $(\mathrm{yr})$ & $44.7 \pm 8.7$ & $39.1 \pm 11.7$ \\
Weight $(\mathrm{kg})$ & $61.9 \pm 10.3$ & $59.5 \pm 10.8$ \\
Height $(\mathrm{cm})$ & $159.2 \pm 5.5$ & $160.2 \pm 11.8$ \\
\hline
\end{tabular}

\section{RESULTS}

Table 4. Intubating Conditions Classification

\begin{tabular}{ccc}
\hline & Group C $(\mathrm{n}=35)$ & Group D $(\mathrm{n}=35)$ \\
\hline Excellent & 4 & 34 \\
Good & 20 & 1 \\
Poor & 4 & 0 \\
Bad & 7 & 0 \\
\hline
\end{tabular}

Values are number of patients. P value is 0.000 . Group C: The group which is injected with $0.9 \%$ normal saline, Group D: The group which is injected dexmedetomidine $1 \mu \mathrm{g} / \mathrm{kg}$.

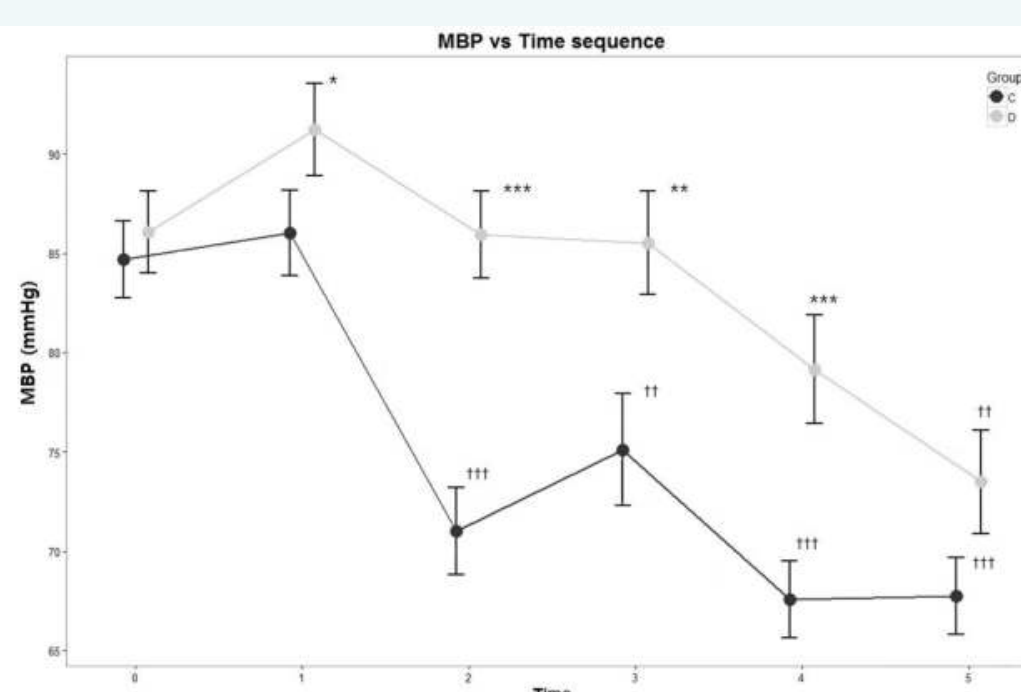

This figure represents the heart rate from starting dexmedetomidine or saline infusion to $5 \mathrm{~min}$ after intubation. $* * *:<0.001, * *:<0.01, *:<0.05$ vs Group C, $\uparrow \dagger \uparrow: 0.001, \dagger \uparrow:<0.01, \uparrow:<0.05$ vs baseline.

T0 : Baseline, T1 : $10 \mathrm{~min}$ after dexmedetomidine infusion, T2 : after Induction $\mathrm{T} 3:$ Immediately after intubation, T4 $: 3 \mathrm{~min}$ after intubation, T5 $: 5 \mathrm{~min}$ after intubation, Group C: The group which is injected with $0.9 \%$ normal saline, Group D: The group which is injected dexmedetomidine $1 \mu \mathrm{g} / \mathrm{kg}$.

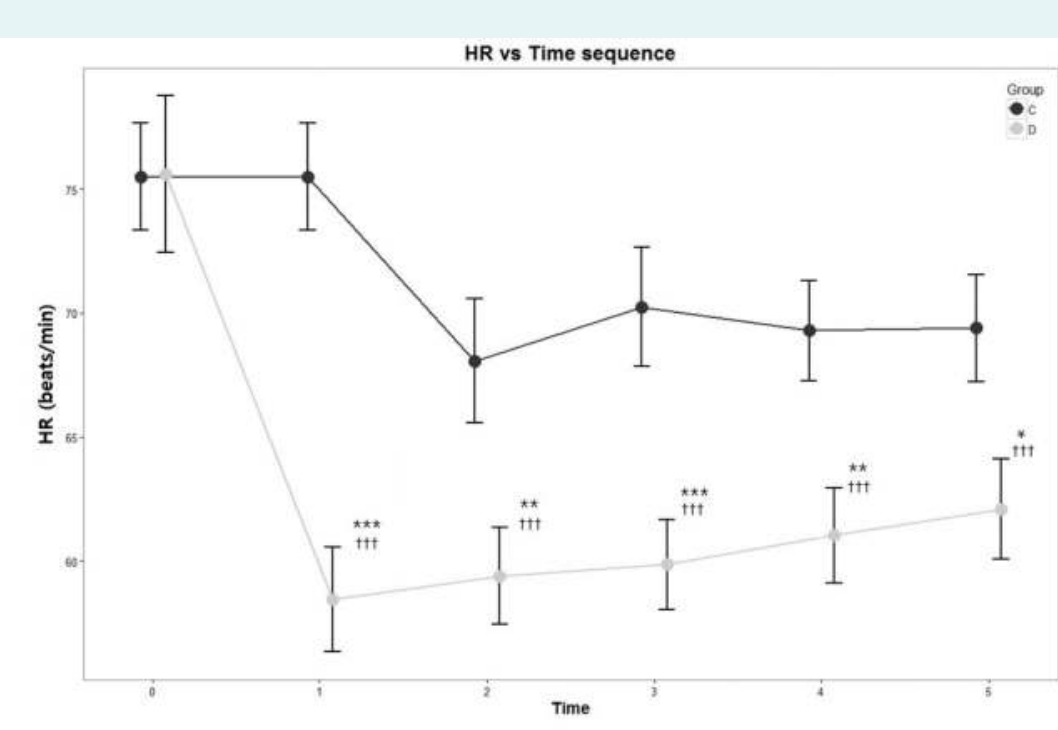

Fig. 2. This figure represents the mean blood pressure from starting dexmedetomidine or saline infusion to $5 \mathrm{~min}$ after intubation.

$* * *:<0.001, * *:<0.01, *:<0.05$ vs Group C, $\uparrow \dagger \uparrow: 0.001, \uparrow \uparrow:<0.01, \dagger:<0.05$ vs baseline

$\mathrm{T} 0$ : Baseline, $\mathrm{T} 1: 10 \mathrm{~min}$ after dexmedetomidine infusion, $\mathrm{T} 2:$ after Induction $\mathrm{T} 3:$ Immediately after intubation, T4 : 3 min after intubation, T5 : 5 min after intubation, Group C: The group which is injected with $0.9 \%$ normal saline, Group D: The group which is injected dexmedetomidine $1 \mu \mathrm{g} / \mathrm{kg}$.

\section{Conclusions}

Dexmedetomidine $1 \mu \mathrm{g} / \mathrm{kg}$ improved the intubating conditions and stabilized hemodynamic changes following anesthetic induction performed using propofol $2 \mathrm{mg} / \mathrm{kg}$ and remifentanil $1.5 \mu \mathrm{g} / \mathrm{kg}$ without a neuromuscular blocking agent. 